Published in final edited form as:

Curr Hypertens Rep. 2012 August ; 14(4): 360-365. doi:10.1007/s11906-012-0279-2.

\title{
Oxidative Stress in the Cardiorenal Metabolic Syndrome
}

\author{
Adam Whaley-Connell and \\ Diabetes and Cardiovascular Center, Harry S Truman VA Medical Center and the University of \\ Missouri-Columbia School of Medicine, Columbia, MO, USA \\ Division of Nephrology and Hypertension, Harry S Truman VA Medical Center and University of \\ Missouri-Columbia School of Medicine, CE427, DC043.0, Five Hospital Dr, Columbia, MO 65213, \\ USA,whaleyconnella@health.missouri.edu
}

\author{
James R. Sowers \\ Diabetes and Cardiovascular Center, Harry S Truman VA Medical Center and the University of \\ Missouri-Columbia School of Medicine, Columbia, MO, USA
}

\section{Abstract}

\begin{abstract}
Excess visceral adiposity contributes to inappropriate activation of the renin-angiotensinaldosterone system despite a state of volume expansion and of salt retention that contributes to subclinical elevations of pro-oxidant mechanisms. These adverse effects are mediated by excess generation of reactive oxygen species (ROS) and diminished antioxidant defense mechanisms. Excess tissue (i.e., skeletal muscle, liver, heart) free oxygen radicals contribute to impairments in the insulin-dependent metabolic signaling pathways that regulate glucose utilization/disposal and systemic insulin sensitivity. The generation of ROS is required for normal cell signaling and physiological responses. It is a loss of redox homeostasis that results in a proinflammatory/ profibrotic milieu that promotes impairments in insulin metabolic signaling, reduced endothelialmediated vasorelaxation, and associated cardiovascular and renal structural and functional abnormalities. These maladaptive processes are increasingly recognized as important in the progression of hypertension in the cardiorenal metabolic phenotype. There is increasing evidence to support a critical role for Ang II signaling through the $\mathrm{AT}_{1} \mathrm{R}$ and aldosterone actions through the MR in conjunction with an altered redox-mediating impaired endothelial, cardiac and renal function in this metabolic phenotype. There are emerging clinical data that indicate that therapies that target the renin angiotensin-aldosterone system (RAAS) also attenuate oxidative stress, and improve endothelial, cardiac and renal functions, which collectively contribute to reductions in hypertension.
\end{abstract}

\section{Keywords}

Hypertension; Cardiorenal syndrome; Oxidative stress; Aldosterone; Obesity; Insulin resistance; Renin-angiotensin-aldosterone system; Redox control

\section{Introduction}

Cardiovascular disease (CVD) and chronic kidney disease (CKD) closely parallel the obesity epidemic, which is increasing in the US. Indeed, there are approximately 70 million

(C) Springer Science+Business Media, LLC 2012

Correspondence to: Adam Whaley-Connell.

Disclosure Dr. Whaley-Connell reported no potential conflicts of interest relevant to this article. 
obese adults in the US and another 70 million with hypertension [1-5]. Data from several population-based studies, such as the National Health and Nutrition Examination Survey (NHANES), suggest a graded and continuous relationship exists between prevalent hypertension and increasing body mass index (BMI) [3-5]. In this regard, obesity is characterized by the presence of insulin resistance, and mounting data support the notion that obese patients exhibit more frequent impairments in insulin metabolic signaling in the vasculature, which results in endothelial dysfunction and manifests clinically as hypertension $[6 \bullet \bullet, 7 \bullet \bullet, 8,9]$.

Importantly, the presence of obesity is now recognized to herald even greater cardiovascular risk, clustering around alterations in systemic and local tissue insulin-dependent biologic responses $[6 \bullet \bullet, 7 \bullet \bullet, 8,9,10 \bullet \bullet, 11]$ (Fig. 1). Insulin resistance implies impairments of metabolic signaling responses to insulin, and impaired glucose transport and utilization in skeletal muscle, liver and fat, as well as cardiovascular and kidney tissue [10••, 11, 12]. Thus, actions of insulin with concurrent resistance give rise to diverse tissue and clinical manifestations that characterize the cardiorenal metabolic syndrome $[7 \bullet \bullet, 13]$.

A chronic low-level, proinflammatory/pro-oxidative state exists that often accompanies insulin resistance and hypertension $[4,7 \bullet \bullet, 12]$. As a result of excess adiposity, subclinical elevations of proinflammatory molecules produced by the liver and adipose tissue include: interleukin-6 (IL-6), C-reactive protein (CRP), PAI-1 levels and fibrinogen levels, which are linked with the development of impaired insulin-dependent glucose utilization and endothelial dysfunction $[\mathbf{7} \bullet$ ]. The presence of insulin resistance is also associated with inappropriate activation of the renin-angiotensin-aldosterone system (RAAS), in part because of increased angiotensinogen and a lipid-soluble aldosterone-stimulating factor release from adipose tissue $[6 \bullet \bullet, 7 \bullet \bullet, 8,9]$. Mounting evidence supports the notion that aldosterone actions mediated through the mineralcorticoid receptor (MR), in addition to angiotensin II (Ang II) acting through its type 1 receptor $\left(\mathrm{AT}_{1} \mathrm{R}\right)$, induce insulin resistance by inhibiting the actions of insulin in vascular and skeletal muscle tissue $[6 \bullet \bullet, 7 \bullet \bullet, 8,9]$. This hormone does this, in part, by promoting NADPH oxidase activity/oxidative stress and endothelial dysfunction through the generation of labile reactive oxygen species (ROS). Thereby, oxidative stress contributes to alterations in redox-sensitive insulin-dependent signaling through phosphatidylinositol-3-kinase (PI3-K) and protein kinase B/Akt. Recent work suggests mammalian target of rapamycin (mTOR)/S6K1 signaling pathways [14, 15••, $16 \bullet \bullet, 17]$. These alterations in redox-sensitive kinases promote metabolic dysregulation that manifests as insulin resistance and hypertension, both prominent features of the cardiorenal metabolic syndrome.

Herein we review putative mechanisms that contribute to oxidative stress in the vasculature and kidney, which promotes metabolic dysregulation and endothelial dysfunction.

\section{The Importance of Insulin Resistance in the Cardiorenal Metabolic Syndrome}

Obese individuals have insulin level elevations required to maintain glucose and fatty acid metabolism in traditional insulin-sensitive tissues such as the skeletal muscle, liver and adipose tissue. Recent work highlights a role in non-traditional insulin-sensitive tissues such as the heart, aorta and kidney [18-21]. It is important to note that resistance to insulin is not uniform in all tissues. The alterations in response to insulin in various tissues are often accompanied by reductions in insulin-mediated metabolic signaling, and downstream impaired glucose transport and utilization in skeletal muscle and cardiovascular tissue lead to impaired nitric oxide (NO)-induced vasodilatation [22, 23, 24••]. Thereby, the accentuation of some actions of insulin with parallel resistance to other actions gives rise to 
diverse clinical manifestations associated with the cardiorenal metabolic syndrome (Fig. 1); sequelae that are a result of activation of the (SNS) sympathetic nervous system, salt sensitivity, inappropriate activation of the RAAS, and increases in inflammation and oxidative stress.

\section{The Role of Aldosterone in Oxidative Stress in the Cardiorenal Metabolic Syndrome}

The RAAS is inappropriately activated in obese individuals who display insulin resistance, despite a state of salt sensitivity and relative volume expansion $[6 \bullet \bullet, 7 \bullet \bullet, 8,9]$. Recent data suggest there are elevations in circulating aldosterone associated with increases in visceral adiposity, and mounting data indicate that adipose tissue displays a local RAAS [25-28]. Visceral adipose tissue has been shown to possess higher levels of angiotensinogen (AOGEN) relative to subcutaneous tissue and also expresses the angiotensin type 1 and 2 receptors $\left(\mathrm{AT}_{1 / 2} \mathrm{R}\right)$, suggesting an autocrine-paracrine role for visceral adipose tissue [29]. Some investigative groups even postulate further that the adipose tissue RAAS may actually regulate systemic blood pressure to some degree [30].

Angiotensin (Ang) II has been traditionally thought of as the main effector peptide of the RAAS [31, 32]. Ang II signaling through the $\mathrm{AT}_{1} \mathrm{R}$ contributes to the deleterious vasoconstrictor effects of Ang II, actions that are opposed by Ang II binding of the $\mathrm{AT}_{2} \mathrm{R}$ under routine conditions. In this context, traditional ligand receptor binding leads to Gprotein-coupled effects of Ang II through phospholipase $C$ with the formation of 1,4,5inositol and DAG versus non-G protein coupled effects through stimulation of tyrosine kinases. Both pathways contribute to activation of NADPH oxidase and other metabolic oxidases to generate the superoxide anion $\left(\cdot \mathrm{O}_{2}^{-}\right)$and other free radicals important in the development of resistance to insulin-dependent metabolic signaling [31, 32].

Extending beyond Ang II as the classical effector peptide, aldosterone is now thought to exert many of the profibrotic, proinflammatory and pro-oxidative effects independent of those of Ang II in the heart, vasculature and kidney [28, 33-35]. Aldosterone has been shown to augment $\mathrm{AT}_{1} \mathrm{R}$-dependent signaling pathways and promote vascular production of oxidative stress through the enzyme complex NADPH oxidase independent of Ang II [35, 36]. In addition, aldosterone has been shown to potentiate the impact of Ang II impairments in endothelium-dependent relaxation both directly and indirectly through increased vascular oxidative stress resulting in reductions in the bioavailable nitric oxide (NO) [35-37]. Additional evidence supports the notion that excess aldosterone promotes cardiovascular tissue remodeling through increases in collagen synthesis and fibrosis, resulting in arterial stiffness, left ventricular hypertrophy and kidney fibrosis [35-38]. In rodent models that display Ang II and aldosterone excess, antagonism of the mineralocorticoid receptor (e.g., the target of aldosterone) attenuates heart and kidney tissue oxidative stress through reductions in NADPH oxidase and thereby improves interstitial fibrosis, tissue remodeling and hypertrophy mechanisms [35-40].

\section{Vascular NADPH Oxidase Generation of Oxidative Stress in the Cardiorenal Metabolic Syndrome}

NADPH oxidase is the enzyme responsible for much of the generation of $\cdot \mathrm{O}_{2}{ }^{-}$in cardiovascular tissue, which contributes to endothelial dysfunction as well as heart and kidney tissue remodeling $[14,15 \bullet \cdot, 16 \bullet, 17,18,41]$. NADPH oxidase is comprised of several membrane and cytosolic subunits that mobilize and activate under various agonists such as Ang II, aldosterone as well as fatty acids [20, 21, 41-43]. gp91 phox (phox=phagocyte oxidase) is now referred to as Nox 2 and p22phox, which together form the 
heterodimer flavocytochrome $\mathrm{b}_{558}$ and comprise the membrane complex. The strategic cytosolic subunit $\mathrm{p} 47^{\mathrm{phox}}$ undergoes phosphorylation and is generally considered the critical subunit for activation of the complex [43]. p67 phox is another cytosolic subunit that facilitates the transfer of the hydride ion from NAD (P)H to FAD upon interaction with the small G-protein Rac. Rac exists inactively, but upon phosphorylation results in activation to $\mathrm{GDP} \rightarrow \mathrm{GTP}$, for example, and translocation to the membrane complex. The final transfer of an electron to form $\mathrm{O}_{2}{ }^{-}$is facilitated by two heme groups present within the $\mathrm{NAD}(\mathrm{P}) \mathrm{H}$ complex.

NADPH generation of ROS serves routine cellular functions [32, 40, 42]. The excess activation and the imbalance in the metabolism of oxygen and production of excess free radicals contribute to "oxidative stress" in the heart, vascular and kidney tissue. ROS regulate pathways critical to normal cell signaling, apoptotic pathways, cell and tissue growth, as well as salt and fluid homeostasis. Free radicals such as $\cdot \mathrm{O}_{2}{ }^{-}$, hypochlorite $\left(\mathrm{ClO}^{-}\right)$, the hydroxyl moiety $(. \mathrm{OH})$, peroxynitrite $\left(\mathrm{ONOO}^{-}\right)$as well as protein and lipid species are transient and cleared by various antioxidant mechanisms.

In the context of obesity, increased exposure to excess fatty acids, Ang II and aldosterone, and even high salt intake promote alterations in signaling pathways that include ion channel functions, mitogenic and transcription factors, and tyrosine kinases/phosphatases [13, 2831]. It is of note that the impact of ROS generated within various components of the vasculature is subject to the local balance of pro- and antioxidant mechanisms, whether it be the heart, aorta or kidney.

\section{Redox Control of Vascular Function in the Cardiorenal Metabolic Syndrome}

Free radical formation is generally divided into generation of ROS or reactive nitrogen species (RNS) known to regulate cell growth and differentiation, smooth muscle relaxation as well as inhibition of platelet adhesion and numerous second messenger systems that promote impairments in endothelial function [12-14, 15••, 16••, 17, 32]. Critical to the metabolic phenotype is the NO radical (NOO) produced by oxidation of the nitrogen atom of L-arginine catalyzed by nitric oxide synthase (NOS). As a potent vasodilator, bioavailable NO is then consumed by ROS; however, there is a predominance of $\cdot \mathrm{O}_{2}{ }^{-}$during oxidative stress, which rapidly reacts with $\mathrm{NO}$ to yield $\mathrm{ONOO}^{-}$, a particularly reactive RNS. ROS also react with $\mathrm{NO}$ in the oxidation of tetrahydrobiopterin $\left(\mathrm{BH}_{4}\right)$ in a process referred to as endothelial NO synthase (eNOS) uncoupling. NOS forms $\cdot \mathrm{O}_{2}{ }^{-}$instead of $\mathrm{NO}$ in the absence of $\mathrm{BH}_{4}$ and is considered another critical source of oxidative stress that promotes endothelial dysfunction. It should be noted that ROS also regulate various mechanisms thought to contribute to chronic disease, which promotes oxidization of cell constituents such as proteins, lipids and DNA largely because of their electrophilic character.

The complex relationship among ROS, normal cell function and disease states such as hypertension can be mitigated by understanding that only in excess can these radicals result in injury, while their roles as mediators of cell signaling are temporally and spatially regulated.

\section{Targeting the RAAS to Improve Redox Control of Vascular Function in the Cardiorenal Metabolic Syndrome}

Experimental evidence from pre-clinical as well as clinical studies suggests targeting the RAAS improves control of hypertension through targeting oxidative stress and improvements in endothelial function [32, 35, 41]. There are sufficient data to support a beneficial effect of targeting reductions in Ang II through either inhibition of the ACE or 
blockade of $\mathrm{AT}_{1} \mathrm{R}$ on oxidative stress and reductions in blood pressure [32, 44]. Data from our laboratory and others suggest that, in rodent models that display inappropriate activation of the RAAS, targeting the MR and recently direct renin inhibition (DRI) improve ROS formation/oxidative stress and result in improved cardiovascular tissue remodeling and metabolic parameters [45-47]. On the clinical level it has been known for some time that RAAS inhibition through ACE inhibition and Ang II receptor blockers (ARBs) improves hypertension control and cardiovascular outcomes, including congestive heart failure (CHF), coronary artery disease and CKD in patients with type 2 diabetes [47]. It is important to note that increasing data on MR antagonism have shown promise in CHF and CKD as well as in individuals with resistant hypertension [6••].

In the context of the cardiorenal metabolic syndrome, there are sufficient preclinical data and mounting clinical data to suggest a beneficial effect of RAAS blockade on insulin resistance and glucose homeostasis [48, 49]. The marker of interest in outcome trials has been new-onset diabetes, extending observations in preclinical models that support that $\mathrm{ACEi}$ or $\mathrm{AT}_{1} \mathrm{R}$ blockade improves insulin-mediated glucose uptake through enhanced microvascular endothelial function, nitric oxide activation, reduced inflammatory response and increased bradykinin levels. However, the impact of MR antagonism or DRI on insulin resistance and glucose homeostasis continues to be an area of active interest.

The role of MR antagonism on blood pressure regulation and insulin sensitivity, from an experimental perspective, focuses on oxidative stress in concert with improved insulindependent glucose uptake as well as attenuated whole-body insulin resistance in skeletal muscles $[6 \bullet \bullet, 9,28]$. However, there has not been definitive clinical evidence to extend these experimental observations. The discrepancy may be due to several reasons in the context of the cardiorenal metabolic syndrome. It is important to note that the MR has a high affinity for both aldosterone and 11 $\beta$-hydroxyglucocorticoids, which exist in lower levels in nonepithelial tissues that allow glucocorticoids to signal through the MR in cardiovascular and metabolic tissue such as skeletal muscle, liver and fat [34]. In the cardiorenal metabolic syndrome circulating gluco-corticoid concentrations are greater than those of aldosterone. Thereby, MR activation by glucocorticoids further potentiates the oxidative stress in the cardiorenal metabolic syndrome.

Regardless of the mechanism, there is convincing evidence to support that interruption of the RAAS at any access point, whether DRI, ACEi or $\mathrm{AT}_{1} \mathrm{R}$ blockade, or antagonism of the MR in humans ameliorates oxidative stress, improves endothelial function and contributes to reductions of hypertension in the cardiorenal metabolic phenotype.

\section{Conclusions}

Obesity contributes to the development of insulin resistance. It is largely thought to be a result of excess visceral adiposity. There is inappropriate activation of the RAAS despite a state of volume expansion and of salt retention that contributes to subclinical elevations of the pro-oxidant mechanisms that are linked to impairments in the insulin-dependent metabolic signaling pathways that regulate glucose utilization/disposal and systemic insulin sensitivity, processes that are increasingly recognized as important in endothelial function and elevations in blood pressure in the cardiorenal metabolic phenotype. There is increasing evidence to support a critical role for aldosterone actions through the MR independent of those of Ang II signaling through the $\mathrm{AT}_{1} \mathrm{R}$ on redox status and endothelial function in this metabolic phenotype. However, it is clear from clinical data that therapies that target the RAAS at any access point, whether DRI, ACEi or $\mathrm{AT}_{1} \mathrm{R}$ blockade, or antagonism of the MR attenuate oxidative stress, improve endothelial function and contribute to reducing hypertension. 


\section{Acknowledgments}

Dr. Sowers has received research support from National Institutes of Health (NIH).

\section{References}

Papers of particular interest, published recently, have been highlighted as:

•• Of major importance

1. Lakka HM, Laaksonen DE, Lakka TA, et al. The metabolic syndrome and total and cardiovascular disease mortality in middle-aged men. JAMA. 2002; 288(21):2709-2716. [PubMed: 12460094]

2. Malik S, Wong ND, Franklin SS, Kamath TV, L'Italien GJ, Pio JR, et al. Impact of the metabolic syndrome on mortality from coronary heart disease, cardiovascular disease, and all causes in United States adults. Circulation. 2004; 110(10):1245-1250. [PubMed: 15326067]

3. Flegal KM, Carroll MD, Kuczmarski RJ, Johnson CL. Overweight and obesity in the United States: prevalence and trends: 1960-1994. Int J Obes Relat Metab Disord. 1998; 22:39-47. [PubMed: 9481598]

4. McFarlane SI, Banerji M, Sowers JR. Insulin resistance and cardiovascular disease. J Clin Endocrinol Metab. 2001; 86(2):713-718. [PubMed: 11158035]

5. Whitlock G, Lewington S, Sherliker P, Clarke R, Emberson J, Halsey J, Qizilbash N, Collins R, Peto R. Prospective Studies Collaboration. Body-mass index and cause-specific mortality in 900 000 adults: collaborative analyses of 57 prospective studies. Lancet. 2009; 373(9669):1083-1096. [PubMed: 19299006]

6. Sowers JR, Whaley-Connell A, Epstein M. The emerging clinical implications of the role of aldosterone in the metabolic syndrome and resistant hypertension. Ann Intern Med. 2009; 150:776783. [PubMed: 19487712] Targeted paper highlighting aldosterone as critical in resistant hypertension.

7. Pulakat L, Demarco VG, Whaley-Connell A, Sowers JR. The impact of over-nutrition on insulin metabolic signaling in the heart and the kidney. Cardiorenal Med. 2011; 1(2):102-112. [PubMed: 22258397] Seminal paper in a journal dedicated to cardiorenal metabolic syndrome.

8. Bomback AS, Klemmer PJ. Interaction of aldosterone and extracellular volume in the pathogenesis of obesity-associated kidney disease. Am J Nephrol. 2009; 30(2):140-146. [PubMed: 19299892]

9. Whaley-Connell A, Sowers JR. Aldosterone and risk for insulin resistance. Hypertension. 2011; 58(6):998-1000. [PubMed: 22215931]

10. Reaven GM, Chen YD. Insulin resistance, its consequences, and coronary heart disease. Must we choose one culprit? Circulation. 1996; 93(10):1780-1783. [PubMed: 8635254] Important early paper highlighting a unique role for insulin resistance independent of diabetes and its contribution to heart disease..

11. Reaven GM. Insulin resistance, cardiovascular disease, and the metabolic syndrome: how well do the emperor's clothes fit? Diabetes Care. 2004; 27(4):1011-1012. [PubMed: 15047666]

12. Pulakat L, Demarco VG, Ardhanari S, Chockalingam A, Gul R, Whaley-Connell AT, Sowers JR. Adaptive mechanisms to compensate for overnutrition-induced cardiovascular abnormalities. Am J Physiol Regul Integr Comp Physiol. 2011 Aug 3. Epub ahead of print.

13. Sowers JR. The heart and the kidneys: partners in disease? Cardiorenal Med. 2011; 1(1):1-2. [PubMed: 22258459]

14. Lambeth JD. Nox enzymes, ROS, chronic disease: an example of antagonistic pleiotropy. Free Radic Biol Med. 2007; 43:332-347. [PubMed: 17602948]

15. Lassegue $\mathrm{B}$, Clempus RE. Vascular $\mathrm{NAD}(\mathrm{P}) \mathrm{H}$ oxidases: specific features, expression, and regulation. Am J Physiol Regul Integr Comp Physiol. 2003; 285:277-297. Very important paper reviewing the role of NADPH oxidase in health and disease..

16. Rey FE, Cifuentes ME, Kiarash A, Quinn MT, Pagano PJ. Novel competitive inhibitor of $\mathrm{NAD}(\mathrm{P}) \mathrm{H}$ oxidase assembly attenuates vascular $\mathrm{O}(2)(-)$ and systolic blood pressure in mice. Circ Res. 2001; 89:408-414. [PubMed: 11532901] Seminal paper defining the role for NADPH oxidase. 
17. Bedard K, Krause KH. The NOX family of ROS-generating NADPH oxidases: physiology and pathophysiology. Physiol Rev. 2007; 87:245-313. [PubMed: 17237347]

18. Hall JE, Brands MW, Dixon WN, Smith MJ Jr. Obesity-induced hypertension. Renal function and systemic hemodynamics. Hypertension. 1993; 22:292-299. [PubMed: 8349321]

19. DeFronzo RA, Cooke CR, Andres R, Faloona GR, Davis PJ. The effect of insulin on renal handling of sodium, potassium, calcium, and phosphate in man. J Clin Invest. 1975; 55:845-855. [PubMed: 1120786]

20. Rocchini AP, Moorehead C, DeRemer S, Goodfriend TL, Ball DL. Hyperinsulinemia and the aldosterone and pressor responses to angiotensin II. Hypertension. 1990; 15:861-866. [PubMed: 2190930]

21. Rocchini AP, Marker P, Cervenka T. Time course of insulin resistance associated with feeding dogs a high-fat diet. Am J Physiol. 1997; 272:E147-E154. [PubMed: 9038864]

22. Heitzer T, Brockhoff C, Mayer B, Warnholtz A, Mollnau H, Henne S, Meinertz T, Munzel T. Tetrahydrobiopterin improves endothelium-dependent vasodilation in chronic smokers: evidence for a dysfunctional nitric oxide synthase. Circ Res. 2000; 86:E36-E41. [PubMed: 10666424]

23. Mollnau H, Wendt M, Szocs K, Lassegue B, Schulz E, Oelze M, Li H, Bodenschatz M, August M, Kleschyov AL, Tsilimingas N, Walter U, Forstermann U, Meinertz T, Griendling K, Munzel T. Effects of angiotensin II infusion on the expression and function of NAD(P)H oxidase and components of nitric oxide/cGMP signaling. Circ Res. 2002; 90:E58-E65. [PubMed: 11884382]

24. Zhang HH, Huang J, Düvel K, Boback B, Wu S, Squillace RM, Wu CL, Manning BD. Insulin stimulates adipogenesis through the Akt-TSC2-mTORC1 pathway. PLoS One. 2009; 4(7):e6189. [PubMed: 19593385] Important paper highlighting the mTOR pathway..

25. Reisin E, Messerli FG, Ventura HO, Frohlich ED. Renal haemodynamic studies in obesity hypertension. J Hypertens. 1987; 5:397-400. [PubMed: 3668243]

26. Granger JP, West D, Scott J. Abnormal pressure natriuresis in the dog model of obesity-induced hypertension. Hypertension. 1994; 23:I8-I11. [PubMed: 8282380]

27. Schorr U, Blaschke K, Turan S, Distler A, Sharma AM. Relationship between angiotensinogen, leptin and blood pressure levels in young normotensive men. J Hypertens. 1998; 16:1475-1480. [PubMed: 9814618]

28. Goodfriend TL, Egan BM, Kelley DE. Aldosterone in obesity. Endocr Res. 1998; 24:789-796. [PubMed: 9888579]

29. Giacchetti GFE, Sardu C, Mariniello B, Garrapa GGM, Gatti C, Camilloni MA, Mantero F. Different gene expression of the RAS in human subcutaneous and visceral adipose tissue. Int $\mathrm{J}$ Obes Relat Metab Disord. 1999; 23(suppl 5):S71.

30. Massiera F, Seydoux J, Geloen A, et al. Angiotensinogen-deficient mice exhibit impairment of diet-induced weight gain with alteration in adipose tissue development and increased locomotor activity. Endocrinology. 2001; 142:5220-5225. [PubMed: 11713218]

31. Cooper R, McFarlane-Anderson N, Bennett FI, et al. ACE, angiotensinogen and obesity: a potential pathway leading to hypertension. J Hum Hypertens. 1997; 11:107-111. [PubMed: 9140797]

32. Cooper SA, Whaley-Connell A, Habibi J, Wei Y, Lastra G, Manrique C, et al. Renin-aldosterone system and oxidative stress in cardiovascular insulin resistance. Am J Physiol Heart Circ Physiol. 2007; 293(4):H2009-H2023. [PubMed: 17586614]

33. Schiffrin EL. Effects of aldosterone on the vasculature. Hypertension. 2006; 47(3):312-318. [PubMed: 16432039]

34. Williams JS, Williams GH. 50th anniversary of aldosterone. J Clin Endocrinol Metab. 2003; 88(6): 2364-2372. [PubMed: 12788829]

35. Brown NJ. Aldosterone and vascular inflammation. Hypertension. 2008; 51:161-167. [PubMed: 18172061]

36. Wei Y, Whaley-Connell AT, Habibi J, Rehmer J, Rehmer N, Patel K, et al. Mineralocorticoid receptor antagonism attenuates vascular apoptosis and injury via rescuing protein kinase $\mathrm{B}$ activation. Hypertension. 2009; 53(2):158-165. [PubMed: 19114643]

37. Hirono Y, Yoshimoto T, Suzuki N, Sugiyama T, Sakurada M, Takai S, Kobayashi N, Shichiri M, Hirata Y. Angiotensin II receptor type 1-mediated vascular oxidative stress and proinflammatory 
gene expression in aldosterone-induced hypertension: the possible role of local renin-angiotensin system. Endocrinology. 2007; 148:1688-1696. [PubMed: 17218415]

38. Stas S, Whaley-Connell A, Habibi J, Appesh L, Hayden MR, Karuparthi PR, et al. Mineralocorticoid receptor blockade attenuates chronic overexpression of the renin-angiotensinII-aldosterone system stimulation of reduced NADPH oxidase and cardiac remodeling. Endocrinology. 2007; 148:3773-3780. [PubMed: 17494996]

39. Whaley-Connell A, Habibi J, Wei Y, Gutweiler A, Jellison J, Wiedmeyer CE, Ferrario CM, Sowers JR. Mineralocorticoid receptor antagonism attenuates glomerular filtration barrier remodeling in the transgenic Ren2 rat. Am J Physiol Renal Physiol. 2009; 296(5):F1013-F1022. [PubMed: 19261739]

40. Nistala R, Whaley-Connell A. Sowers JR Redox control of renal function and hypertension. Antioxid Redox Signal. 2008; 10(12):2047-2089. [PubMed: 18821850]

41. Paravicini TM, Touyz RM. NADPH oxidases, reactive oxygen species, and hypertension: clinical implications and therapeutic possibilities. Diabetes Care. 2008; 31(Suppl 2):S170-S180. [PubMed: 18227481]

42. Griendling KK, Sorescu D, Ushio-Fukai M. NAD(P)H oxidase: role in cardiovascular biology and disease. Circ Res. 2000; 86:494-501. [PubMed: 10720409]

43. Li JM, Mullen AM, Yun S, Wientjes F, Brouns GY, Thrasher AJ, Shah AM. Essential role of the NADPH oxidase subunit p47 (phox) in endothelial cell superoxide production in response to phorbol ester and tumor necrosis factor-alpha. Circ Res. 2002; 90:143-150. [PubMed: 11834706]

44. Cohn JN. Reducing cardiovascular risk by blockade of the reninangiotensin-aldosterone system. Adv Ther. 2007; 24(6):1290-1304. [PubMed: 18165212]

45. Lastra G, Habibi J, Whaley-Connell A, Manrique C, Appesh L, Hayden MR, Rehmer J, Patel K, Ferrario CM, Sowers JR. Direct renin inhibition reduces oxidative stress, and improves insulinstimulated glucose transport and insulin resistance in skeletal muscle in the TG(mRen2)27 rat. Endocrinology. 2009; 150(6):2561-2568. [PubMed: 19246535]

46. Habibi J, Whaley-Connell A, Hayden MR, DeMarco VG, Schneider R, Sowers SD, Karuparthi P, Ferrario CM, Sowers JR. Renin inhibition attenuates insulin resistance, oxidative stress, and pancreatic remodeling in the transgenic Ren2 rat. Endocrinology. 2008; 149(11):5643-5653. [PubMed: 18653711]

47. Abdellatif AA. The role of renin inhibition in treating the hypertensive patient with diabetes: a summary of preclinical and clinical evidence. Expert Rev Cardiovasc Ther. 2012; 10(2):251-263. [PubMed: 22292880]

48. The DREAM Trial Investigators. Effect of ramipril on the incidence of diabetes. N Engl J Med. 2006; 355:1551-1562. [PubMed: 16980380]

49. NAVIGATOR Study Group. Effect of valsartan on the incidence of diabetes and cardiovascular events. N Engl J Med. 2010; 362(16):1477-1490. [PubMed: 20228403] 


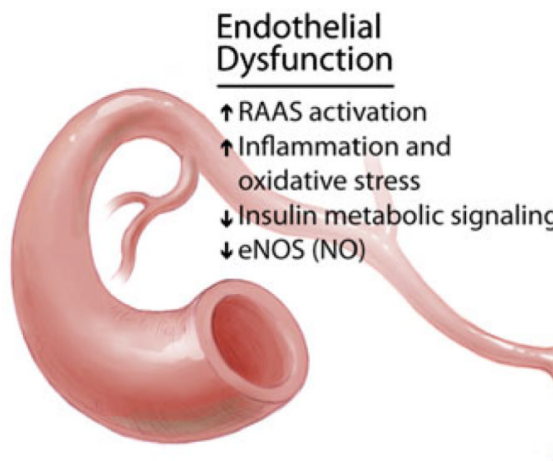

Endothelial

DAAS activation

$\uparrow$ Inflammation and

Visceral Adipose Tissue

(macrophage-induced production of inflammatory adipokines)

Skeletal Muscle Insulin Resistance

$\uparrow$ RAAS activation

$\uparrow$ Inflammation and oxidative stress

$\downarrow$ Insulin metabolic signaling

Insulin metabolic signaling

$\downarrow$ Glucose transport and utilization

\section{Kidney}

$\uparrow$ RAAS activation

$\uparrow$ Inflammation and

oxidative stress

$\uparrow$ Glomerular dysfunction

$\uparrow$ Tubulointerstitial fibrosis

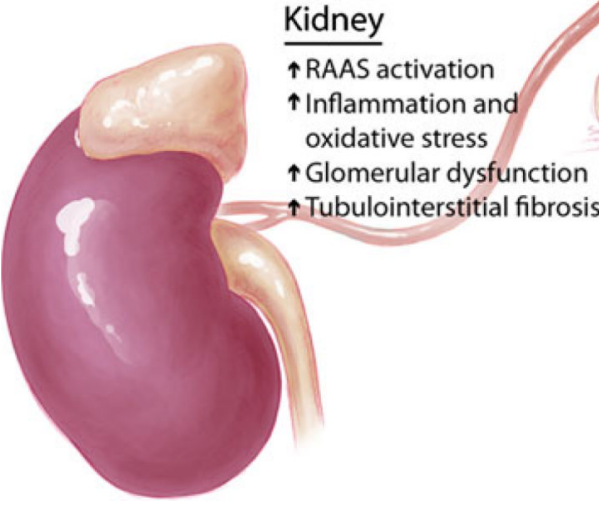

\section{Left Ventricular} Hypertrophy

$\uparrow$ RAAS activation

$\uparrow$ Inflammation and oxidative stress

$\downarrow$ Insulin metabolic signaling $\uparrow$ Cardiomyocyte hypertrophy $\uparrow$ Interstitial fibrosis

Fig. 1.

The central role of visceral adipose tissue in mediating systemic responses to insulin sensitivity in cardiovascular and kidney disease. eNOS, endothelial nitric oxide synthase; NO, nitric oxide; RAAS, renin-angiotensin-aldosterone system 